\title{
DINÂMICA IMOBILIÁRIA NA CIDADE DO NATAL/RN
}

\author{
Osmar Faustino Oliveira ${ }^{1}$ \\ Manoel Raymundo de Carvalho Neto ${ }^{2}$ \\ José Geraldo Pimentel Neto ${ }^{3}$ \\ Flávio Antônio Miranda de Souza ${ }^{4}$
}

\section{Resumo}

A dinâmica imobiliária pode ser definida como uma somatória de processos que evidenciam a transformação e valoração sobre o uso do solo em uma lógica de produção de imóveis construídos ou de lotes ditos urbanizados. O objetivo do presente trabalho é discutir o mercado imobiliário em Natal em uma perspectiva econômica. A metodologia consiste em uma revisão bibliográfica. Por meio dos dados, ficou perceptível que alguns bairros de Natal são mais valorizados do que outros, atraindo assim, maiores investimentos e especulação imobiliária, encarecendo essas áreas, o bairro de Nova Parnamirim é um exemplo.

Palavras-chave: Urbanização Emergente. Valorização Imobiliária. Boom Imobiliário.

\section{REAL ESTATE DYNAMICS IN NATAL CITY / RN}

\begin{abstract}
Real estate dynamics can be defined as a summation of processes that evidence the transformation and valuation of land use in a logic of production of constructed real estate or urbanized so-called lots. The objective of this work is to discuss the real estate market in Natal from an economic perspective. The methodology consists of a bibliographical review. Through the data, it was noticeable that some neighborhoods of Natal are more valued than others, attracting, thus, bigger investments and real estate speculation, making more expensive these areas, the district of Nova Parnamirim is an example.
\end{abstract}

Keywords: Emerging Urbanization. Real estate valuation. Boom Real Estate.

\footnotetext{
${ }^{1}$ Mestre em Desenvolvimento Urbano pela Universidade Federal de Pernambuco. Especialista em Mercado de Capitais pela Universidade Federal do Rio Grande do Norte. Especialista em Projetos Sociais e Políticas Públicas pela Faculdade de Ciências Humanas Esuda. Email: osmarfaustino@yahoo.com.br.

${ }^{2}$ Mestre em Gestão e Economia da Saúde pela Universidade Federal de Pernambuco (UFPE). Especialista (MPA) em Gestão Pública e Gerência de Cidades pela (FACINTER). Email: manoelneto.ufpe@ gmail.com.

${ }^{3}$ Doutor em Desenvolvimento Urbano pela UFPE. Coordenador do NIT do ITEP. Email: gerageo@ gmail.com.

${ }^{4}$ Doutor em Planejamento Urbano - Oxford Brookes University (1998). Pós-doutorado em políticas públicas na University of Texas at Austin (2002). Email: fdesouza67@gmail.com.
} 


\section{DINÁMICA INMOBILIARIA EN LA CIUDAD DE LA NATAL / RN}

\section{Resumen}

La dinámica inmobiliaria puede ser definida como una suma de procesos que evidencian la transformación y valoración sobre el uso del suelo en una lógica de producción de inmuebles construidos o de lotes dichos urbanizados. El objetivo del presente trabajo es discutir el mercado inmobiliario en Natal desde una perspectiva económica. La metodología consiste en una revisión bibliográfica. Por medio de los datos, se percibió que algunos barrios de Navidad son más valorados que otros, atrayendo así, mayores inversiones y especulación inmobiliaria, encarando esas áreas, el barrio de Nova Parnamirim es un ejemplo.

Palabras clave: Urbanización Emergente. Valorización Inmobiliaria. Boom Inmobiliario.

\section{INTRODUÇÃO}

Para entender a dinâmica urbana da cidade de Natal é essencial compreender a construção dos bairros, nos quais ocorre o desenvolvimento imobiliário (FERREIRA; SILVA, 2007). A compreensão sobre os processos de expansão da área metropolitana de Natal, passa pela análise do setor imobiliário, articulado a consolidação dos destinos turísticos, principalmente voltados para um público estrangeiro. A dinâmica imobiliária pode ser definida como uma somatória de processos que evidenciam a transformação e valoração sobre o uso do solo em uma lógica de produção de imóveis construídos ou de lotes ditos "urbanizados". Amplas faixas da área metropolitana, especificamente as áreas litorâneas, passam a ser ocupadas por tipologias imobiliárias até então pouco expressivas.

Para caracterizar as "novas dinâmicas" foram utilizados dois indicadores: a) a quantidade e localização dos empreendimentos imobiliários formais (flats, condomínios fechados horizontais e verticais, condhotéis e resorts), voltados a um período mais longo de permanência; b) e o volume de investimentos estrangeiros na economia do RN, no período de 2001 a 2006 (FERREIRA; SILVA, 2007)

Entretanto, é necessário evidenciar que as "novas dinâmicas" não excluem os tradicionais produtos imobiliários existentes em Natal e em sua área conturbada. Ocorre que após o encerramento dos financiamentos pelo BNH (em 1986), os setores da construção civil e imobiliárias passaram por uma reestruturação em suas estratégias de atuação, voltando seus produtos para a classe média e média alta natalense, nos anos de 1990. A Verticalização concentrada em alguns bairros da cidade, os condomínios fechados em áreas de valorização 
SOCIEDADE E

TERRITÓRIO
OLIVEIRA, Osmar Faustino

CARVALHO NETO, Manoel Raymundo de

PIMENTEL NETO, José Geraldo

SOUZA, Flávio Antônio Miranda de

imobiliária e o lançamento de tipologias de alto custo de comercialização foram algumas das estratégias do mercado imobiliário formal na década passada. O turismo, em finais da década de 1990, modificou esse cenário, atraindo um novo comprador capitalizado em euro ou dólar.

O presente estudo, pretende mostrar essa dinâmica imobiliária na cidade do Natal e seus aspectos no mercado de imóveis.

\section{REFERENCIAL TEÓRICO}

A dinâmica imobiliária por meio do deslocamento das atividades do setor, é referência para compreender as mudanças na estrutura intra-urbana. Então, a ação ligada aos capitais incorporadores retentores do solo urbano e também dos capitais construtores elaboradores da moradia, incidirá na mudança de uso do solo. Pelo meio da transformação do uso, em que os capitais obtêm lucro, e isso os obriga a investirem onde houver possibilidades de transformação, ou seja, o movimento do capital imobiliário é delimitado por uma estrutura espacial pré-existente e pelos valores sobre o ambiente arquitetado futuro. É por meio dessa lógica, que a estruturação intra-urbana e a residencial em particular, tem como atitude decisiva a ação dos capitais imobiliários através da busca de um "mark-up" urbano conformando espaços distintos na cidade (ABRAMO; FARIA, 1998).

Para realizarem seus ganhos fundiários, o capital imobiliário emprega estratégias de ação, tais como a atuação de forma concentrada, delimitando áreas de valorização, e a inovação do produto que será oferecido, no caso a habitação. Essa inovação não se refere apenas aos atributos do imóvel em si, como altera o padrão de ocupação de toda uma área, valorizando-a em relação às outras áreas da cidade. As estratégias são externalidades, que são incorporadas ao valor dos imóveis, definindo assim, acesso diferenciado das famílias com diferentes rendimentos. De tal modo, a estratégia de inovação para atrair demanda, se traduz na oferta do bem habitação com todos os seus atributos essenciais, como características físicas, e extrínseco como a acessibilidade que a localização da moradia permite usufruir. Essas qualidades simulam os valores de uso do imóvel, por sua condição essencial de abrigo do homem, como também representa um ativo da economia familiar, e sua aquisição levará em consideração a sua valorização futura na estrutura de preços imobiliários na cidade (ABRAMO, 1998). A estratégia de inovação da habitação para atrair demanda, serve para diferenciar o novo imóvel 
do estoque existente, e com isso produz um efeito "depreciador" no estoque, que perde a atratividade anterior, elevando a importância das novas construções (ABRAMO; FARIA, 1998).

\section{RESULTADOS}

Identificados os capitais que permitem as novas dinâmicas no setor imobiliário e turístico, faz-se necessário compreender a relação espacial dos empreendimentos construídos e com as sedes municipais da área metropolitana. Foram identificados juntos aos órgãos ambientais de licenciamento (IDEMA e secretarias municipais), cerca de 370 empreendimentos imobiliários; destes, 53,69\% localizam-se em área não litorânea e 43,61\% adjacente a linha de praia. Natal com 41,22\% do total, seguido pelo município de Parnamirim com $\mathbf{2 5 , 2 6 \%}$ e Nísia Floresta com $\mathbf{2 1 , 2 7 \%}$, perfazem um total de quase $88 \%$ de toda a nova dinâmica imobiliária (ver gráfico 1).

\section{Gráfico 1. Empreendimentos imobiliários na faixa litorânea na RMN em 2006.}

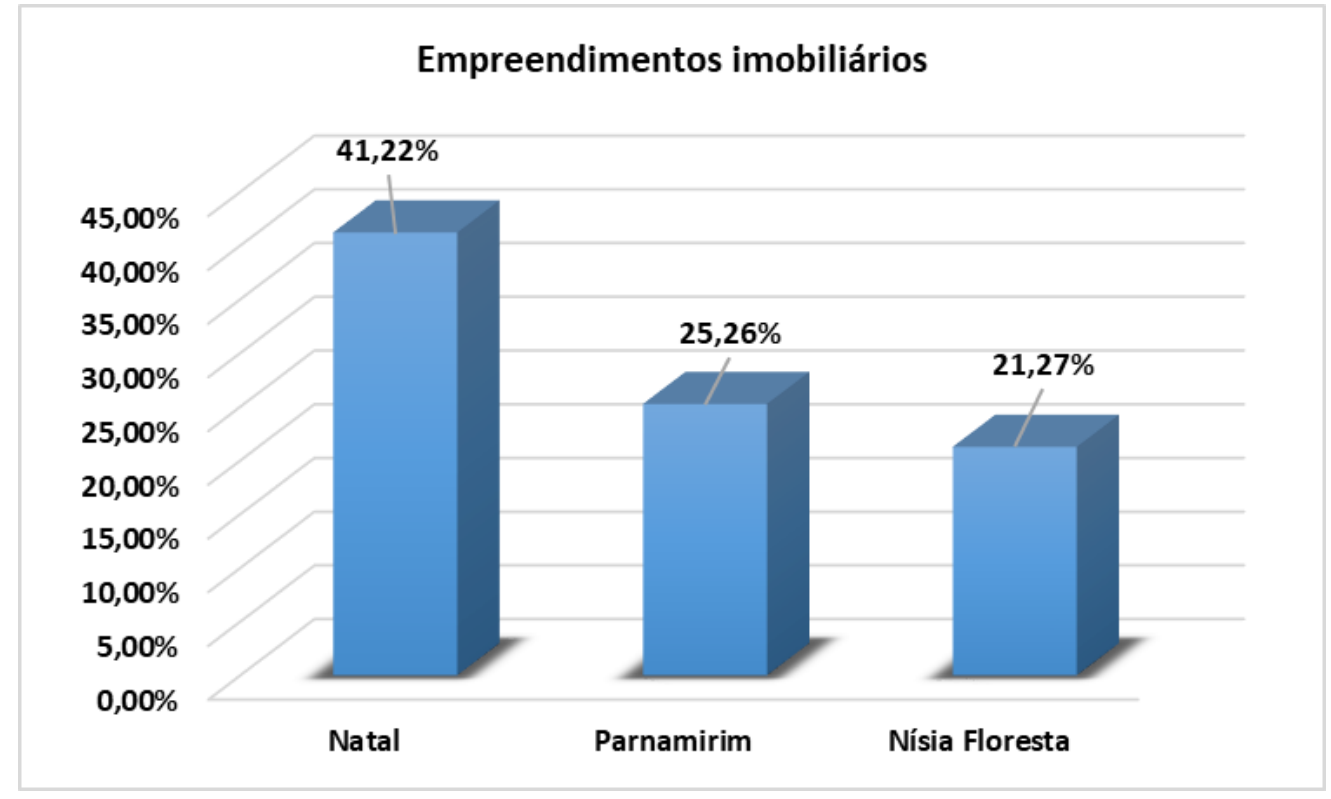

Fonte: (FERREIRA; SILVA, 2007). Elaboração própria.

A figura 1 ilustra o Eixo de Investimentos e Valorização Imobiliária em Natal segundo as zonas mais valorizadas por ordem a sua valorização imobiliária a zona sul está no mapa na cor vermelha, é a zona mais valorizada. Em segundo a leste que está na cor amarela, é a 
SOCIEDADE E

TERRITÓRIO
OLIVEIRA, Osmar Faustino

CARVALHO NETO, Manoel Raymundo de

PIMENTEL NETO, José Geraldo

SOUZA, Flávio Antônio Miranda de

segunda mais valorizada. A Oeste na cor azul está em terceira posição e a Norte na cor verde em quarta.

Figura 1: Eixo de Investimentos e Valorização Imobiliária - EIVI

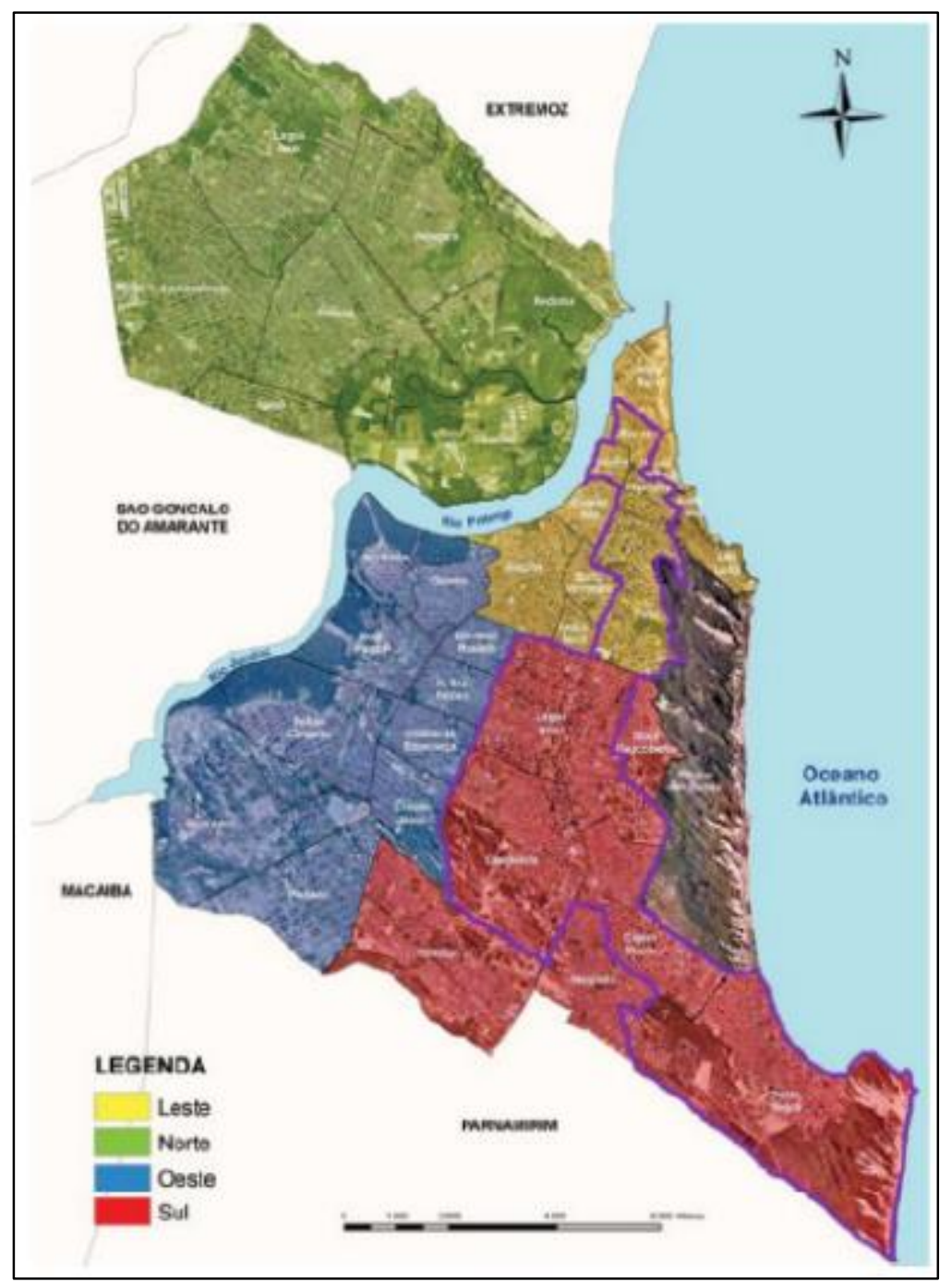

Fonte: SILVA, 2015.

Uma caracterização mais recente da Tipologia Socioespacial foi feita por Clementino e Pessoa (2010), no âmbito dos estudos do Observatório das Metrópoles. Esta, contudo, considerou toda a área da Região Metropolitana de Natal (RMN), classificando as áreas nas seguintes categorias: superior, médio superior, médio, médio inferior, popular operário, popular, popular agrícola e agrícola. No referido estudo não se considerou como unidade da pesquisa os bairros em si, mas as AEDs. Estas, por sua vez, são o conjunto de setores 
censitários; áreas de ponderação ou áreas de expansão demográfica, que se constituem como a base para a construção da Tipologia Socioespacial do estudo. É possível verificar, com os dados da pesquisa supracitada, que continua existindo uma concentração, do que se chama na pesquisa de "camadas superiores" em poucas áreas da RMNatal, sobretudo localizadas no eixo de desenvolvimento mais importante da cidade de Natal. Os chamados "espaços superiores" estão concentrados nesse eixo de desenvolvimento e englobam a maior parte da "Elite Dirigente" e boa parte da Elite Intelectual, além de uma participação inferior das "ocupações médias" (CLEMENTINO e PESSOA, 2010).

Nesse sentido, é notória a concentração dos segmentos mais ricos da população natalense no eixo de concentração, no qual a cidade desenvolve-se e produz o marketing. A esse respeito, foi feito uma pesquisa, a qual elaborou um levantamento das últimas gestões da prefeitura de Natal, no que concerne às logomarcas utilizadas como forma de marketing urbano. Via-se no Governo de Garibaldi Filho (1985-1988) a utilização de um símbolo histórico para a cidade: a Fortaleza dos Reis Magos, construída no período colonial pelos portugueses para ser o forte contra os invasores.

O Governo de Aldo Tinôco (1993-1996), por sua vez, utiliza-se da imagem da fachada histórica da prefeitura. O primeiro Governo de Wilma de Faria (1997-2000) utiliza-se da imagem do Farol de Mãe Luiza, também um dos principais atrativos históricos da cidade. É no segundo mandado de Wilma de Faria (2001-2002) que se pode ler, através da sua nova logomarca, a busca por uma formulação de uma imagem de cidade moderna para Natal, apresentando o "Pórtico dos Reis Magos" (GUIMARÃES, 2010).

Analisando as logomarcas usadas na publicidade das gestões das prefeituras de Natal, Guimarães (2010) chegou à conclusão de que essas logomarcas se orientam de acordo com o eixo de expansão urbana da cidade, em direção à Região Sul, mais privilegiada do que a região Oeste e Norte, no que tange os aspectos gerais de infraestrutura. Medeiros (2011) traz em sua tese a discussão do que denomina EIVI - Eixo de Investimentos e Valorização Imobiliária. Este eixo compreende, como o próprio nome sugere, os bairros que estão contidos na área de maior investimento e, consequentemente, de maior valorização imobiliária.

Na figura 1 fica evidente que, no eixo observado pela autora, encontram-se os bairros de status da cidade de Natal. Interessado no principal corredor viário que liga a RMN em formação, Petronilo Júnior (2007) constrói o conceito de "Espaço Central das Atenções" (ECA). Este se constitui como o corredor de $22 \mathrm{Km}$ que vai "da primeira passarela de 
SOCIEDADE E

TERRITÓRIO
OLIVEIRA, Osmar Faustino

CARVALHO NETO, Manoel Raymundo de

PIMENTEL NETO, José Geraldo

SOUZA, Flávio Antônio Miranda de

Parnamirim, limite entre os bairros Boa Esperança e Cohabinal/Parnamirim - BR - 101, até a Maternidade Januário Cicco, localizada no bairro de Petrópolis/Natal” (SILVA JÚNIOR, 2007, p. 49). O autor afirma que "o que há hoje de melhor na infraestrutura construída da cidade, concentra-se no eixo Sul-Leste, evidenciando que a mesma obedeceu a um explícito direcionamento no sentido dos espaços atinentes às elites e à atividade turística" (SILVA, 2015, Págs. 2 e 3).

A análise do espaço da cidade aparece como uma extensão em que não é apenas espacial, mas também de forma temporal, ao mesmo tempo em que mostra uma intensa contradição nos processos de apropriação do espaço pela sociedade. Porque o espaço urbano é produto da consolidação de relações sociais que se realizam em um determinado momento. Então essa indissociabilidade de tempo e espaço ganha dimensão quando é avaliada através da intervenção do uso, que revela os modos de apropriação. Isto é, no diagnóstico geográfico, o tempo revela-se na maneira de assimilação do espaço, através do uso do espaço como condição de realização da vida humana. Na morfologia pode-se encontrar marcas daquilo que resiste e daquilo que traz a marca da transformação, ou seja, as marcas das mudanças, mais ou menos radicais feitas pelas intervenções do planejamento.

A autora Leal (2015) discute que existe empreendimentos que gera grandes impactos na paisagem da cidade. Ela ilustra bem o caso de Recife, mas tudo isso que ela discute, cabe relacionar com Natal. Por exemplo a mudança do Aeroporto de Parnamirim para São Gonçalo do Amarante, gerou impactos como a valorização dos imóveis, criação de novos empregos e etc. além de gerar empregos, o aeroporto muda completamente a paisagem onde ele se instalou. As imagens 2 e 3 irão mostrar o antes e o depois da construção do aeroporto. Vale ressaltar o quanto de empregos formais essa construção gerou para a população. Mesmo depois de construído, existe uma quantidade significativas de pessoas trabalhado em tal aeroporto. Além, é claro de valorizar os imóveis localizados nas proximidades.

Figura 2: Local da construção do aeroporto de Natal 


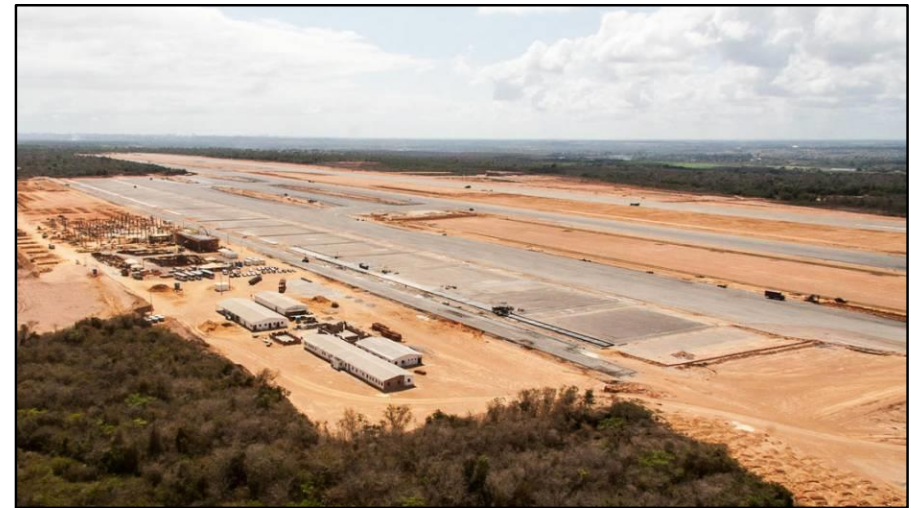

Fonte: Veja.com ${ }^{5}$.

\section{Figura 03: Aeroporto Internacional Aluízio Alves}

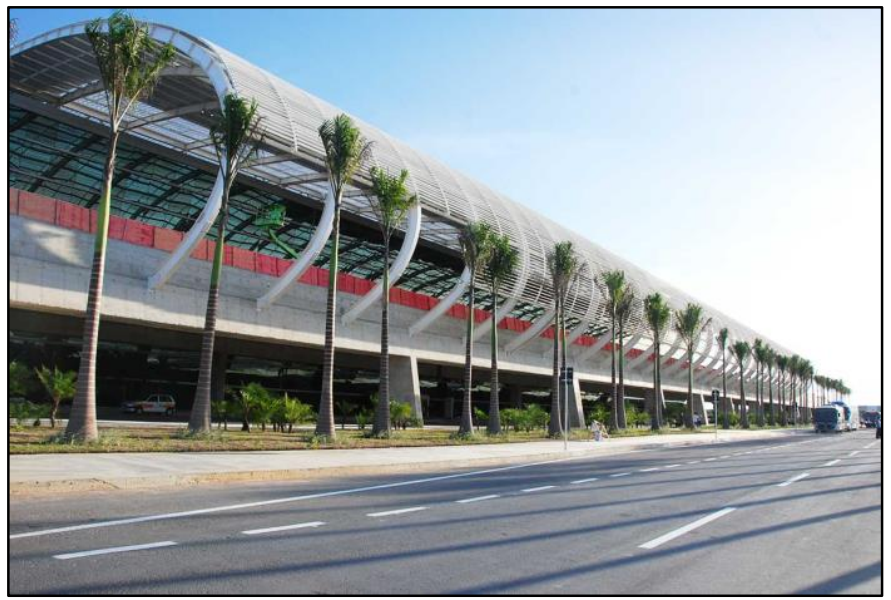

Fonte: Apartamento $702^{6}$

As Figuras 4 e 5 ilustram o Morro do Careca na cidade do Natal, é interessante fazer uma conexão com o Lamas chama de território, que nada mais é, uma extensão da superfície terrestre no qual vivem um grupo de pessoas, ou melhor, é o espaço estabelecido pelo homem, em oposição ao que poderíamos referir por espaço natural e que não tenha ainda sido habitado pelo homem. É o espaço onde o homem desempenha a sua ação, modificando-se as condições físicas, estabelecendo a sua ordem (LAMAS, 2004).

\section{Figura 04: Morro do Careca no século XX}

\footnotetext{
${ }^{5}$ Disponível em: <http://veja.abril.com.br/economia/aeroporto-de-natal-a-15-meses-da-copa-85-da-obra-estapor-fazer/> Acesso em ago. 2017

${ }^{6}$ Disponível em: <https://apartamento702.com.br/saiba-como-chegar-aeroporto-de-natal-pagando-r-250/> Acesso em ago. 2017
} 
OLIVEIRA, Osmar Faustino

TERRITÓRIO

CARVALHO NETO, Manoel Raymundo de

PIMENTEL NETO, José Geraldo

SOUZA, Flávio Antônio Miranda de

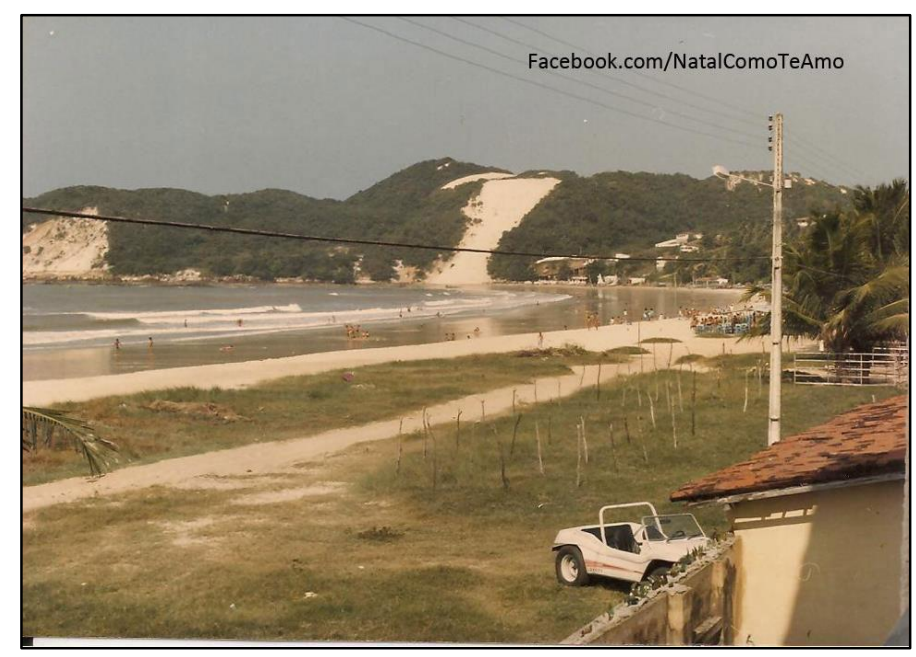

Fonte: Curiozzzo ${ }^{7}$.

\section{Figura 05: Morro do Careca na Atualidade na cidade do Natal}

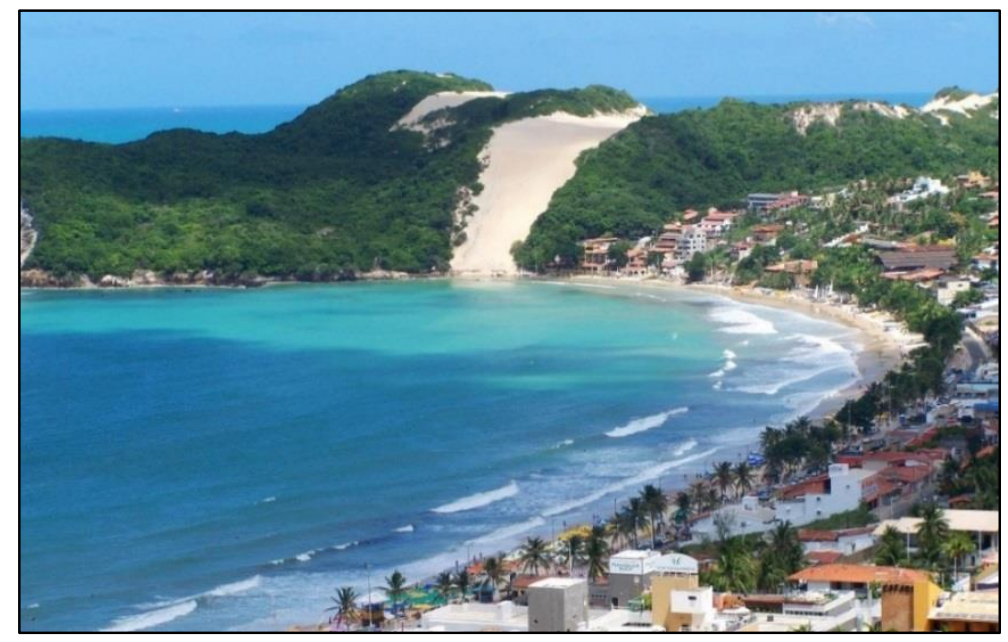

Fonte: DicaNordeste ${ }^{8}$.

O morro do careca ao seu redor era inabitado, era um espaço natural. Logo mais, tronase um espaço humanizado, com a construção de casas, edifícios e etc. As Figuras 3 e 4 ilustram o morro do careca na cidade do Natal, onde era praticamente esquecido até o século passado, apenas os pescadores moravam ao redor. Com o boom do setor imobiliário esses pescadores foram "expulsos" e grande hotéis, restaurantes e condomínios de luxo foram construídos. Os

\footnotetext{
${ }^{7}$ Disponível em: <https://curiozzzo.com/2015/07/08/as-20-melhores-fotos-antigas-de-natal-rn-muitas-vocenunca-viu/> Acesso em ago. 2017

${ }^{8}$ Disponível em: <http://dicanordeste.com.br/cinco-lugares-para-visitar-em-natal/> Acesso em ago. 2017
} 
pescadores ficaram isolados de todo esse luxo, estão localizados em uma pequena vila. Existe o conjunto de Ponta Negra, em que só há casas, hotéis, restaurantes, boates exclusivamente para turistas. Enquanto que as pessoas de renda baixa estão localizadas na vila de Ponta Negra. É interessante o poder que tem o capital, em mudar completamente a conjuntura de uma cidade. Como também transformar a imagem de uma cidade.

O morro do careca é uma paisagem exuberante, atrai muitos turistas. Os restaurantes, hotéis com vista para o morro são bastantes apreciados pelos turistas. Nos últimos anos, foi proibido a subida no morro, pois estava destruindo a imagem bela. Em que a areia estava descendo. Daí vale apena ressaltar que a autora Ermínia Maricato (2001), chama de recuperação de áreas consolidadas. Como também é proibido construir casas muito próximo ao morro, pois pode ocorrer um desmoronamento.

Uma cidade em que há bastantes favelas, é um cenário negativo, como já mencionado antes no presente trabalho, o processo de urbanização causa tanto efeitos positivos, quanto efeitos negativos. As favelas são efeitos negativos desse processo que vem ocorrendo nas Regiões Metropolitanas do Brasil. Em Natal existe muitas favelas, mas são bastantes escondidas. Os edifícios "cobrem" digamos assim esse impacto negativo. Elas ficam “invisíveis" aos olhos dos turistas. Já a cidade de Salvador, por exemplo é bastante visível a favelização. Basta entrar na cidade que é possível observar tal coisa. A cidade do Natal é maquiada neste aspecto, os edifícios de luxo disfarçam tal ponto negativo.

A autora Ermínia Maricato (2001), chama a atenção para a importância da recuperação de áreas consolidadas, como as favelas por exemplo. Ela cita em seu livro: Brasil, cidades: alternativas para crise urbana página 121 que:

\footnotetext{
A requalificação ou recuperação de áreas deterioradas implica em considerar o patrimônio público ou privado, já construído, como poupança, num processo de complementação com obras urbanas (urbanização de favelas ou de loteamentos) ou recuperação de edifícios deteriorados (cortiços), ou mesmo de ampliação de moradias existentes. Fazem parte dessa política vários e importantes programas: Urbanização e regularização de favelas; recuperação e prevenção de áreas sujeitas a riscos de desmoronamentos; urbanização e regularização de loteamentos ilegais; reforma e ou ampliação de moradias resultantes do processo de autoconstrução; recuperação de áreas de preservação ambiental ocupadas por moradias; reforma de cortiços e requalificação urbanísticas de áreas centrais degradadas (MARICATO, 2001 pág. 121.
} 


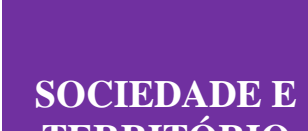

TERRITÓRIO
OLIVEIRA, Osmar Faustino

CARVALHO NETO, Manoel Raymundo de

PIMENTEL NETO, José Geraldo

SOUZA, Flávio Antônio Miranda de

O combate sobre a cidade ocupada precariamente, ilicitamente, vagarosamente, com insuficientes recursos financeiros e técnicos, públicos e privados, não podem se dar como um conjunto de intercessões precisas segundo (MARICATO, 2001).

Porém, é de grande importância a prevenção de áreas, pois impactos negativos como a favelização pode e muito prejudicar a imagem da cidade. Portanto, deve ser cuidada, preservada de forma que deixe a cidade com um aspecto de perfeição aos olhos das pessoas. Como também, deve-se tomar medidas para que as pessoas vivam em constante harmonia com a paisagem em sua volta. Os governos devem fazer com que as pessoas tenham uma digna moradia, e tentar amenizar os impactos negativos da favelização.

O homem tem o poder de mudar completamente uma a cidade, basta ele querer. As figuras 6 e 7 são a prova disso, mas essa é uma atuação das autoridades para receber um grande evento que irá mudar completamente a cidade aos olhos do mercado internacional. A destruição e construção de um novo estádio, trouxe empregos para o setor da construção civil, várias pessoas foram contratadas para erguer tal monumento. Ocorreu vários debates sobre a construção desse monumento, se seria realmente rentável para a cidade, houve controvérsias.

\section{Figura 06: Antigos estádios da cidade do Natal}

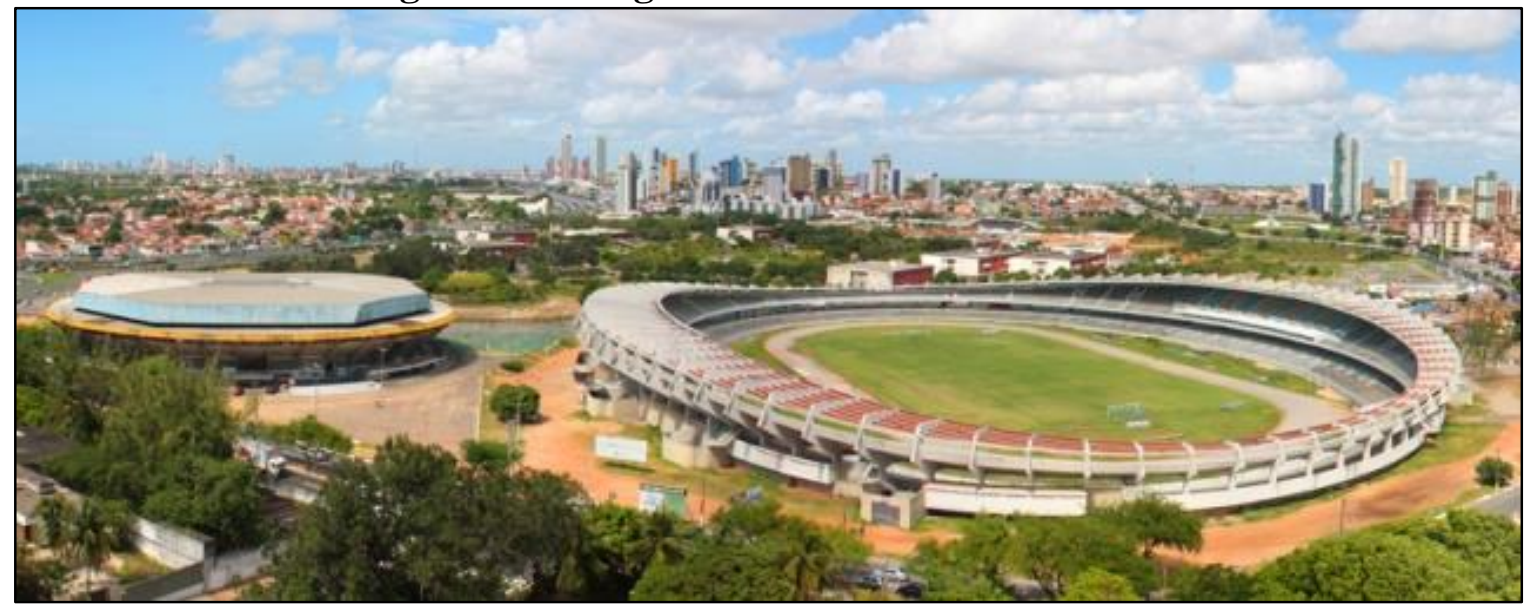

Fonte: Tribuna do Norte. Disponível em: http://www.tribunadonorte.com.br/noticia/bens-domachadinho-e-machadao-sao-leiloados/194265 cesso em: 17/01/2019. 
Figura 07: Atual estádio da cidade do Natal

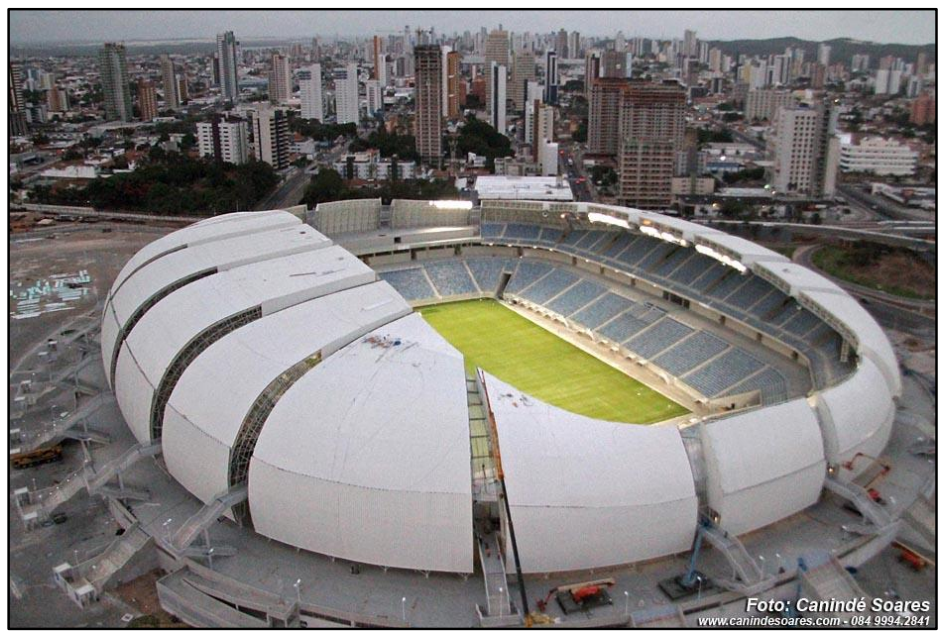

Fonte: Jean Souza 9 .

Como diria Leal (2015) esse estádio é um bom exemplo de um Master Project, que tem como objetivo atrair investimentos estrangeiros e mostrar as cidades para o mercado internacional. Esse novo estádio o Arena das Dunas foi construído para receber um grande evento, a Copa de 2014, realizada no Brasil. Foi preciso destruir o velho estádio, no caso eram dois, o Machadão e o Machadinho para poder construir o Arena das Dunas. Isto é bastante interessante porque o autor Schumpeter chama isso de destruição criativa, em que destrói o velho, para reconstruir o novo.

Entre os exemplos de Master Project estão as Cidades e os Bairros Planejados que têm surgido como uma inovação no produto imobiliário, alastrar-se nas áreas periurbanas das metrópoles. Com isso, as intervenções físicas de grande impacto, amparadas por consideráveis investimentos públicos e privados, adjuntas à construção de uma imagem atrativa da cidade para o mercado global, caracterizam um modelo de desenvolvimento apoiado no que David Harvey denomina empreendedorismo urbano (LEAL, 2015).

Esta citação da autora Leal é bastante interessante, pois é o que realmente está acontecendo nas regiões metropolitanas do Brasil. Tanto é que a autora até cita que David

9 Disponível em: <http://www.jeansouza.com.br/arena-das-dunas/tce-aponta-sobrepreco-em-estruturasusadas-na-arena-das-dunas-na-copa/> Acesso em ago. 2017. 
SOCIEDADE E

TERRITÓRIO
OLIVEIRA, Osmar Faustino

CARVALHO NETO, Manoel Raymundo de

PIMENTEL NETO, José Geraldo

SOUZA, Flávio Antônio Miranda de

Harvey já analisava isso, esse empreendedorismo urbano. Os Martes Project têm essa finalidade, atrair investimentos e servir de vitrine para o mercado global.

As legendas Cidades Planejadas e Cidades Inteligentes é uma forma de marketing para as grandes empresas para comerciarem seus produtos imobiliários, como também, termos de um novo formato de Convenção Urbana e de Governança Corporativa. As inovações na tipologia e morfologia dessas novas Cidades Planejadas são os megaempreendimentos em espaços loteados e privados para a construção de cidades dentro de cidades, aglomerando em um só local. Como por exemplo os shoppings, hotéis, hospitais, escolas, imóveis residenciais, lojas comerciais, entre outros (LEAL, 2015).

Isso tem sua importância, pois gera mais empregos para a população. Com isso, aumenta o processo de urbanização. Havendo o lado positivo, que é o aumento de empregos. Como também, o lado negativo, a favelização.

A Figura 8 ilustra os bairros da cidade do Natal, a parte em Vermelho se encontra o bairro de Ponta Negra sendo o bairro em que o mercado imobiliário deu um "boom" é um dos bairros mais caros de se morar, ou seja, é um bairro em que se aloca turistas.

O processo de transformação da cidade de Natal ocorreu de maneira seletiva e intensificou a produção desigual do espaço, por haver privilegiado uma parcela da população com renda mais elevada e, em consequência, propicia espaços exclusivos para que essa demanda se ponha em áreas nobres, como o bairro de Ponta Negra. Ao analisarmos as características do solo urbano na cidade de Natal, como a localização, os atributos urbanos, podemos perceber os interesses dos diversos agentes produtores do espaço para extrair renda da terra. Nesse sentido, Natal possui um aspecto de cidade-mercadoria.

Estudar as políticas públicas, como também, as políticas de infraestrutura urbana, configura-se em solidificações das ações estatais na cidade em que é complacente no entendimento dos diferentes padrões de conformação do território. A qualidade dos espaços residenciais não é o resultado da distância em relação ao centro ou da evolução histórica da cidade, mas é também o efeito das políticas públicas, que podem transformar esta qualidade através da criação de infraestruturas de equipamentos e serviços. 
Figura 8: Bairros de Natal

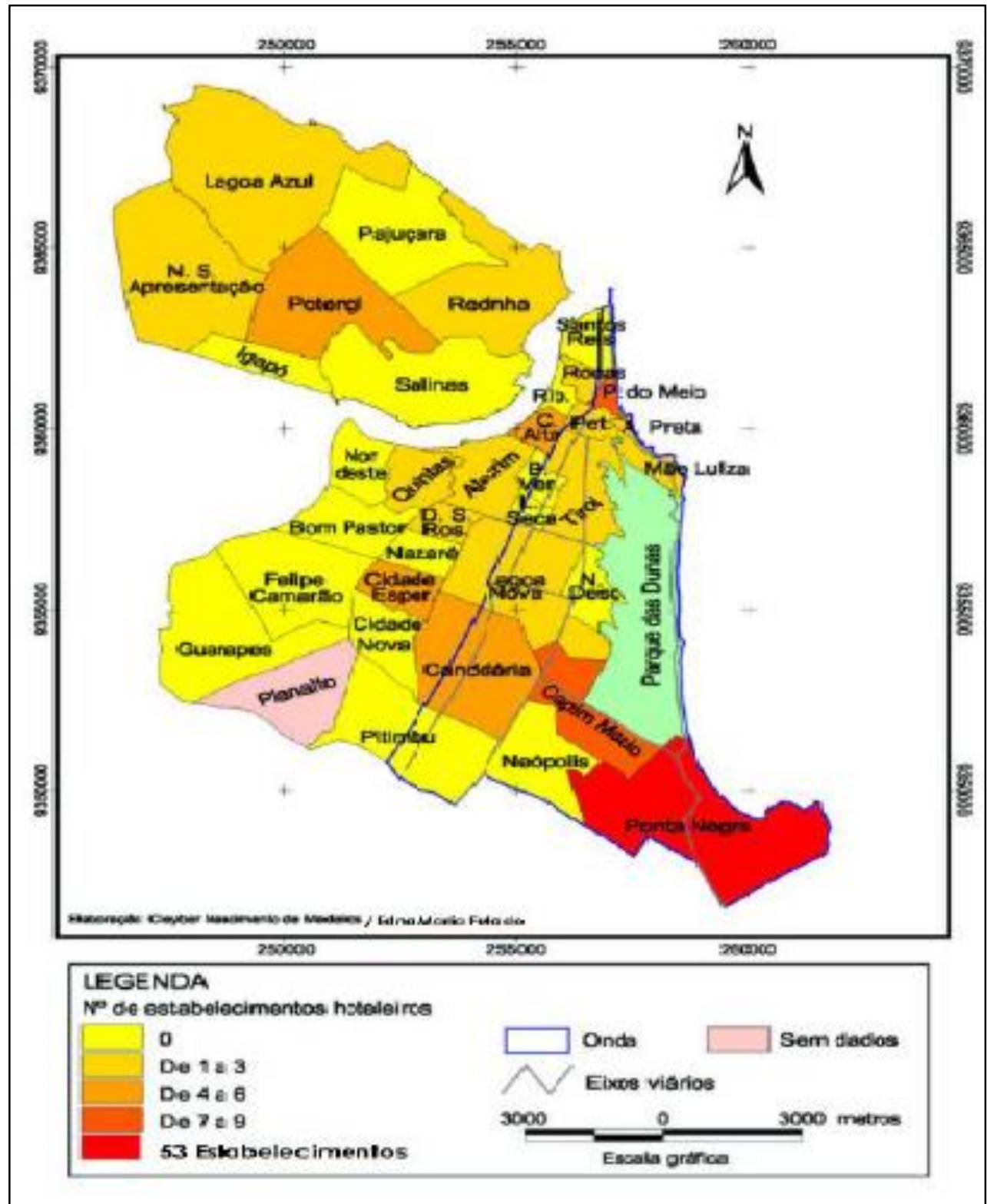

Fonte: Queiroz, 2010.

A própria atuação do Estado no espaço urbano, por meio das políticas públicas, pode contribuir para criar, reforçar ou reduzir mecanismos de segregação. O Estado tem forte influência na produção desses espaços segregados, porque sua atuação no ambiente edificado, por meio de investimentos em infraestrutura e em outros equipamentos públicos, gera valorizações de certas áreas e desvalorização de outras. Isso faz com que a população mais 
SOCIEDADE E

TERRITÓRIO
OLIVEIRA, Osmar Faustino

CARVALHO NETO, Manoel Raymundo de

PIMENTEL NETO, José Geraldo

SOUZA, Flávio Antônio Miranda de

pobre não possa enfrentar com os custos dos benefícios, devido a mecanismos de renda da terra e seja deslocada para outras áreas, distantes e desprovidas de infraestrutura básica e equipamentos públicos, incluindo, desse modo, seus gastos com transporte e sua exposição a variados tipos de risco (BICHIR, 2009).

Além da dimensão espacial, outras vertentes, contemporâneas principalmente no âmbito da economia e da demografia, advertem a importância de fatores individuais no entendimento das condições de acesso as políticas públicas. Essas características sociais e demográficas da população são alvos que poderiam estimular maior acesso a subsídios e maior conhecimento sobre os mecanismos de funcionamento e os canais de acesso a certas políticas públicas.

Existe várias presunções explicativas para as condições de acesso a políticas públicas, principalmente quando se trata dos grupos mais pobres da população. Uns enfoques destacam aspectos individuais dessas populações, suas características socioeconômicas e demográficas, tais como sexo, idade, renda, etc. vários diagnósticos destacam a relevância da atuação estatal na promoção dos serviços e políticas, assinalando para as diferentes motivações que os agentes estatais, principalmente as burocracias que incluem ou não para expandir os serviços para os grupos mais carentes, visando à sua reprodução.

A importância do estádio Arena das Dunas para a dinâmica imobiliária do seu entorno não se restringe nesses casos, pois ele chega a dar nome a empreendimentos, que se utilizam claramente da proximidade com o estádio como maior meio de venda, tanto para quem quer encontrar o "bem morar", quanto para quem quer investir. O empreendimento da Capuche recebeu o nome de Residencial Corais das Dunas, em clara alusão à proximidade com o estádio mais esperado da cidade. Outro empreendimento que aproveitou a "Arena das Dunas" para valorização é o "Quartier Lagoa Nova", que é um lançamento da Cyrela Plano \& Plano e Abreu. Segundo divulgação de uma empresa de comunicação, a expectativa pré-copa era a de dinamização e valorização imobiliária do bairro de Lagoa Nova (SILVA, 2015).

Associada a essa dinâmica imobiliária, a localização da Arena das Dunas também fortaleceu o mercado do turismo nas suas proximidades. $\mathrm{O}$ Banco Nacional de Desenvolvimento Econômico e Social (BNDES) aprovou um financiamento de 10 milhões de reais para a construção de uma unidade do Hotel Íbis. Essa operação dá-se no contexto do 
Programa BNDES ProCopa Turismo, o qual visa a modernização do parque hoteleiro nacional para a realização da Copa do Mundo FIFA Brasil 2014 (PORTAL DA COPA, 2012). Outro empreendimento, o "Porto Arena", foi batizado com esse nome na busca de uma associação com o projeto mais esperado da cidade. Mesmo estando distante em torno de $3 \mathrm{Km}$, o empreendimento da Ecocil agrega valor com o discurso da Copa do Mundo e da proximidade do novo estádio, vendendo a ideia de que "o Porto Arena se encontra no bairro da Candelária, a menos de cinco minutos da Arena das Dunas, que sediará os jogos da Copa do Mundo 2014 em Natal (SILVA, 2015).

A cidade do Natal nos últimos anos vem se expandido no que se refere aos condomínios residenciais. O bairro Nova Parnamirim (figuras 09 e 10) é considerado pelo setor Imobiliário como uma das melhores áreas para investir, devido a disponibilidade de terreno, infraestrutura básica e proximidade do centro de Natal. "Esse eixo de Nova Parnamirim, próximo à Avenida Abel Cabral e a BR-101 é muito procurada pelo Mercado Imobiliário devido a estrutura que já possui" explica a gerente regional da Cyrela Plano e Plano. No bairro, tem tudo o que a população precisa, escola, supermercados, transporte coletivo e etc.. Então, o bairro se torna atrativo tanto para o mercado imobiliário para investir, como atrativo para as pessoas quererem morar neste bairro.

\section{Figura 09: Bairro Nova Parnamirim}

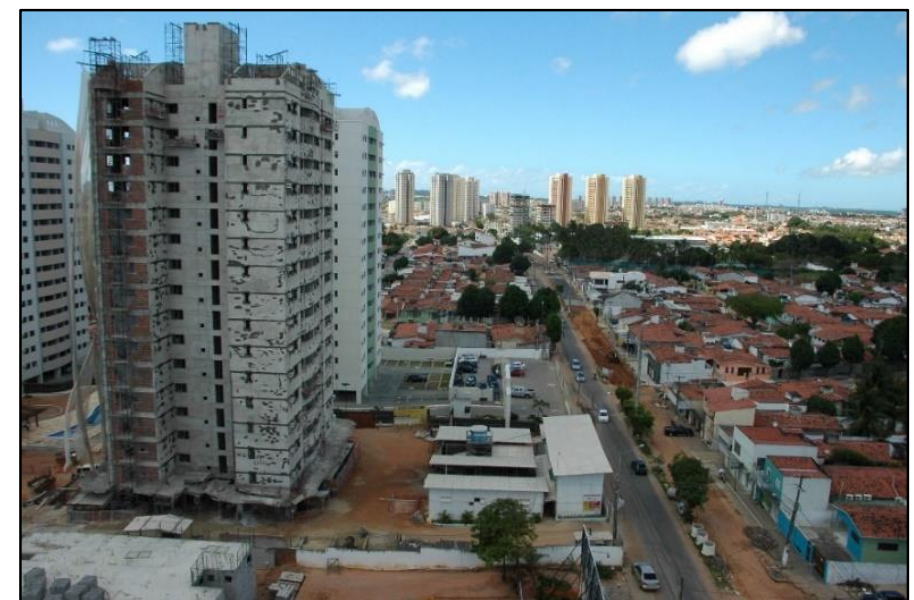

Fonte: Tribuna do Norte. Disponível em: http://www.tribunadonorte.com.br/noticia/nova-parnamirim-espacosupervalorizado/194599 Acesso em 18/2/2019.

Figura 10: Apartamentos Nova Parnamirim 


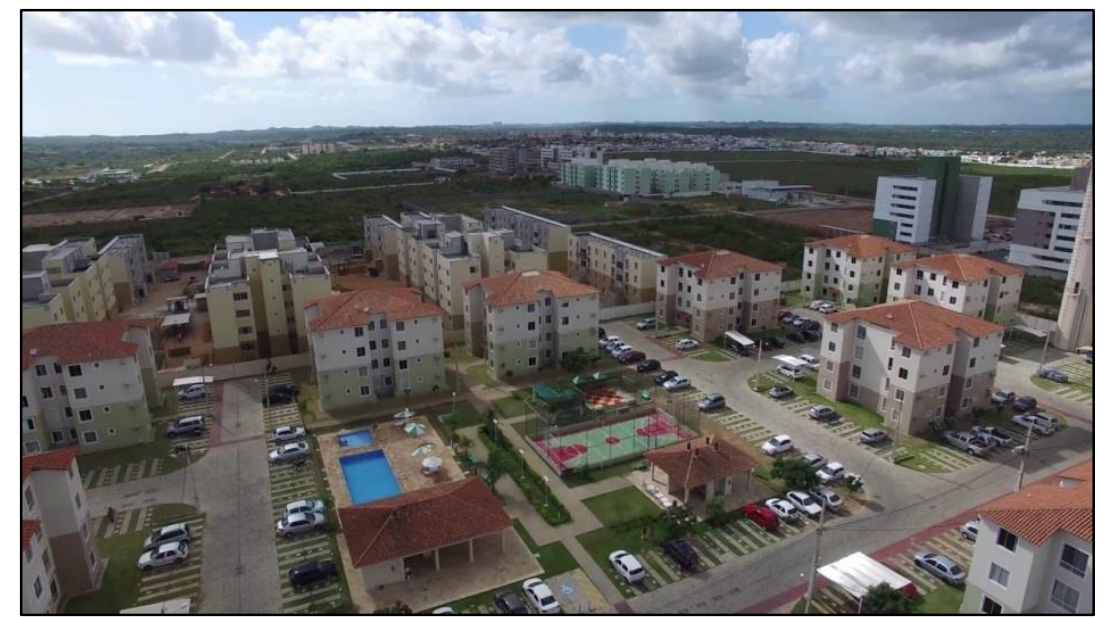

Fonte: Imóveis e Imóveis. Disponível em:http://www.imoveiseimoveisltda.com.br/imovel/631539/apartamentovenda-parnamirim-rn-nova-parnamirim Acesso em 18/03/2019.

Segundo a Prefeitura do Natal ${ }^{10}$ os melhores bairros para apartamentos em Natal como Alto da Candelária, Petrópolis, Capim Macio, Morro Branco, Tirol, Ponta Negra, Lagoa Nova e Nova Parnamirim. Infelizmente, nem todas as pessoas estão aptas a comprar ou alugar apartamento. Isto porque a grande maioria desses investimentos se baseia em financiamentos a longo prazo, com taxas de juros muitas vezes elevadas pelas pressões da inflação e uma incerteza premente de instabilidade econômica.

Alguns fatores contribuem na busca por terrenos e imóveis, inclusive, para fins especulativos, são eles: localização geográfica privilegiada, ofertas de serviços especializados, investimentos públicos e privados e implantação de novos serviços. Nos primeiros anos deste século, investidores estrangeiros, em busca de lucros futuros, faziam aquisições de terrenos, visando a sua valorização, seguindo a lógica da especulação imobiliária. Na cidade de Natal, há muito tempo que a especulação imobiliária ocorre de forma acelerada e seletiva. Pode-se observar que na zona sul da cidade, com a construção de novos condomínios fechados horizontais e verticais, existe uma supervalorização imobiliária dessas áreas, sobretudo, com a concentração da população de maior poder aquisitivo (BARBOSA, 2014; (PREFEITURA MUNICIPAL DO NATAL, 2008).

${ }^{10}$ https://natal.rn.gov.br/ 
No entanto, nas zonas Leste, Oeste e Norte também apresentam áreas com altos índices de valorização, sendo alvo constante da ação de agentes imobiliários visando obtenção de lucros.

Costa (2000) ao avaliar a verticalização em Natal identificou que esse processo não somente atribuiu novas características à moradia, mas colaborou significativamente para uma segregação espacial e para uma ampla inserção do capital urbano. Neste processo as áreas privilegiadas tendem a receber do poder público um cuidado maior com a dotação de infraestrutura urbana pertinente para torná-las mais valorizadas e para o empreendedor imobiliário (BARBOSA, 2014).

A compra, venda e aluguéis de imóveis tem suporte integrante de bancos públicos e privados no financiamento do empreendimento, além disso, o setor de construção atua na configuração do espaço urbano, pressionando o governo por melhores investimentos em determinados bairros da cidade considerados, por vezes, desvalorizados devido à conjuntura espacial, social e econômica que possuem, uma vez que o poder público é responsável por regulamentar, controlar e fiscalizar o mercado imobiliário e os agentes deste segmento.

Natal está subdivida em quatro Regiões Administrativas, sendo elas Norte, Sul, Leste e Oeste, compreendendo um total de 36 bairros. Para efeito de ilustração a Figura 3 apresenta alguns aspectos acerca da capital potiguar. As áreas consideradas nobres, como as localizadas na zona sul da cidade, por exemplo, são servidas de uma boa infraestrutura. Ao longo dos últimos anos, essa área tem experimentado uma supervalorização que se reflete na elevação de preço. Pode-se notar no gráfico 1. Os dados contemplam o número de alvarás de construções $^{11}$ e habite-se ${ }^{12}$ emitidos entre julho de 2007 a novembro de 2013 , na cidade de Natal/RN.

\footnotetext{
${ }^{11}$ Documento emitido pela prefeitura do município onde a construção está localizada que licencia a execução da obra. Disponível em: http://www.colegiodearquitetos.com.br/dicionario/2009/02/o-que-e-alvara-deconstrucao/

${ }^{12}$ Ao ser concedido o Habite-se, o proprietário tem a garantia de que a construção seguiu corretamente tudo o que estava previsto no projeto aprovado e em eventuais substituições aprovadas pelos órgãos responsáveis. Disponível em: https://estadodeminas.lugarcerto.com.br/app/noticia/colunas/francisco-maianetto/2016/09/26/interna_franciscomaia,49570/o-que-e-e-para-que-serve-o-habite-se.shtml
} 
SOCIEDADE E

TERRITÓRIO
OLIVEIRA, Osmar Faustino

CARVALHO NETO, Manoel Raymundo de

PIMENTEL NETO, José Geraldo

SOUZA, Flávio Antônio Miranda de

Gráfico 1: Alvará de construção e habite-se por zonas no período 2007-2013.

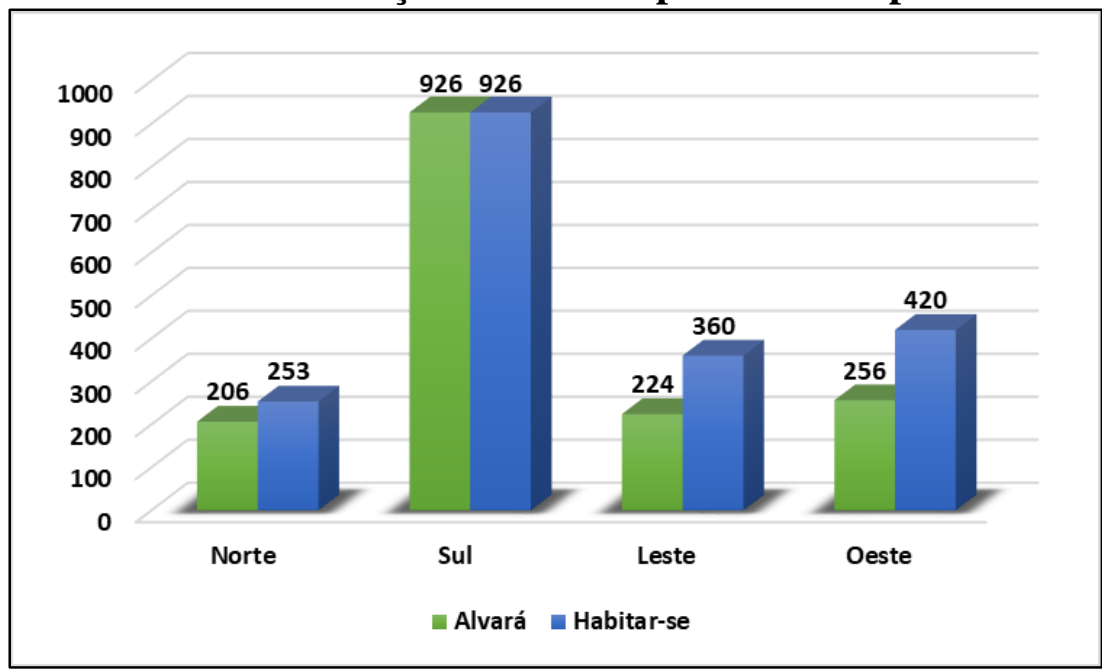

Fonte: Barbosa, 2014, pág. 30. Adaptado pelo autor.

Os bairros cujas populações apresentam alto poder aquisitivo estão localizados na zona leste Petrópolis e Tirol e na zona sul Ponta Negra, Lagoa Nova e Capim Macio. Os mesmos têm se destacado no número de emissões de alvarás e habite-se, ou seja, atraíram grande parte dos investimentos imobiliários no período (ver gráfico 1).

É preciso compreender a relação entre a renda da terra, a localização e, consequentemente, a formação do preço da terra, para a formação dos valores de uso, considerando, pois, que determinadas partes do espaço, no caso da moradia, por exemplo, são desiguais e singulares. O acesso é desigual porque nem todos, na mesma proporção, têm o poder aquisitivo para adquirir terra urbana. Por outro lado, é singular por não ser possível a reprodução do mesmo imóvel, nas mesmas condições, com a mesma localização (RIBEIRO, 1997). Assim, a terra urbana vazia acaba gerando, em meio à malha urbana, oportunidades de novas formas de uso e ocupação, acelerando as disputas por melhor localização e contribuindo para a especulação imobiliária. O Estado como regulador do uso do solo e provedor de infraestruturas urbanas e serviços desempenha um papel primordial neste processo (SILVA, 2015). 


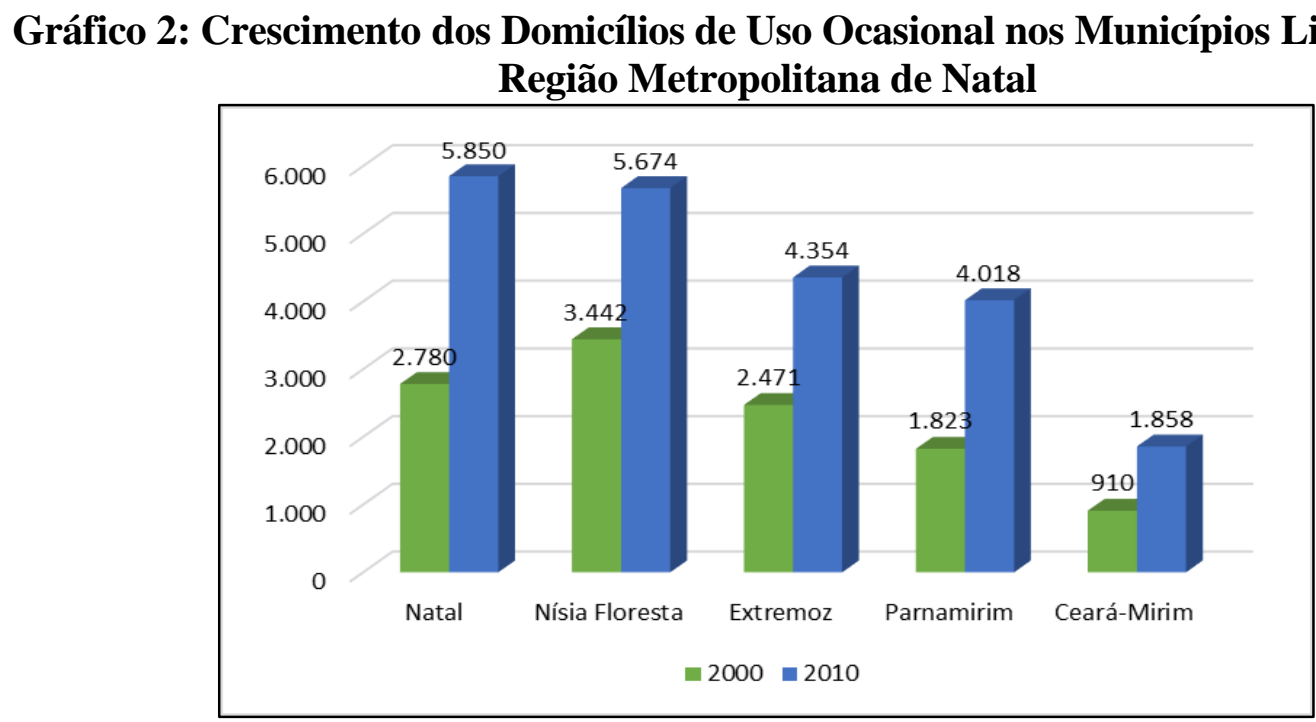

Fonte: IBGE (2000; 2010). Elaboração própria.

No Gráfico 2, os dados indicam os altos de crescimento dos DUOs entre os anos de 2000 e 2010. O município de Natal registra o maior número de residências secundárias em 2010, diferentemente do ano 2000, quando Nísia Floresta aparecia em primeiro lugar. É importante ressaltar que o crescimento dos DUOs em Natal está relacionado à constituição de uma nova demanda - os turistas estrangeiros - que começaram a procurar essa modalidade de imóvel na capital potiguar, a partir da conclusão da primeira etapa do PRODETUR/RN, quando aumenta a frequência dos turistas internacionais na destinação local.

\section{CONSIDERAÇÕES FINAIS}

Portanto, o espaço assume hoje em dia uma importância fundamental, já que a Natureza se transforma, em seu todo, numa forma produtiva. Porque todos os lugares foram atingidos, de maneira direta ou indireta, pelos imperativos do processo produtivo, criam-se, paralelamente, seletividades e hierarquias de utilização com a concorrência ativa ou passiva entre os diversos agentes. Lugar de uma reorganização das funções entre as diferentes frações de território. Cada ponto do espaço torna-se então importante, efetivamente ou potencialmente. Sua importância decorre de suas próprias virtualidades, naturais ou sociais, preexistentes ou adquiridas segundo intervenções seletivas.

Como ocorre uma mundialização da produção, as possibilidades de cada lugar se afirmam e se diferenciam em nível mundial. Dada a crescente internacionalização do capital e a ascensão das firmas transnacionais, em que observar-se-á uma tendência à fixação mundial 
SOCIEDADE E

TERRITÓRIO
OLIVEIRA, Osmar Faustino

CARVALHO NETO, Manoel Raymundo de

PIMENTEL NETO, José Geraldo

SOUZA, Flávio Antônio Miranda de

e não mais nacional dos custos de produção e a uma igualização das taxas de lucros graças à mobilidade internacional do capital ao passo que a procura dos lugares mais rentáveis será uma constante.

Além da dimensão espacial, outras vertentes, contemporâneas principalmente no âmbito da economia e da demografia, advertem a importância de fatores individuais no entendimento das condições de acesso as políticas públicas. Essas características sociais e demográficas da população são alvos que poderiam estimular maior acesso a subsídios e maior conhecimento sobre os mecanismos de funcionamento e os canais de acesso a certas políticas públicas.

O mercado imobiliário investiu em áreas bem localizadas, ou seja, na zona sul de Natal, o bairro de Nova Parnamirim foi contemplado com esse boom imobiliário. O Bairro de Ponta Negra também é bastante valorizado por ser um bairro de turistas.

\section{REFERÊNCIAS}

ABRAMO, Pedro. Regulação Urbana e o Regime Urbano: A Estrutura Urbana, Sua Reprodutibilidade e o Capital. Ensaios FEE, Porto Alegre, 1995.

ABRAMO, Pedro. Revista Brasileira de Estudos Urbanos e Regionais A Cidade ComFusa: a mão inoxidável do mercado e a produção da estrutura urbana nas grandes metrópoles Latinoamericanas - v.9, n.2, 2007.

ABRAMO, Pedro; FARIA, Teresa Cristina. Mobilidade Residencial Na Cidade Do Rio De Janeiro: Considerações Sobre Os Setores Formal E Informal Do Mercado Imobiliário. XI Encontro Nacional de Estudos Populacionais da ABEP. São Paulo. 1998.

BARBOSA, Maikon C. B. Dinâmica Espacial do Município de Natal/RN: Análise do setor Imobiliário no Período 2007-2013. Monografia apresentado ao Departamento do curso de Economia da Universidade Federal do Rio Grande do Norte. Natal,2014.

BICHIR, Renata Mirandola. Determinantes do acesso a Infraestrutura Urbana no município de São Paulo. Revista Brasileira de Ciências Sociais (RBCS) - VOL. 24 N. 70 junhos/2009.

CLEMENTINO, Maria do Livramento; et.al. Região Metropolitana De Natal Cartilhas Produto 5. Núcleo RMNatal Observatório das Metrópoles. Natal/RN, 2007. 
CLEMENTINO, Maria do Livramento. Regiões Metropolitanas no Brasil: Visões do presente e do futuro. XIV Coloquio Internacional de Geocrítica Las utopías y la construcción de la sociedad del futuro Barcelona, 2-7 de mayo de 2016.

FERREIRA, Angela Lúcia; SILVA, Alexsandro Ferreira Cardoso. Novas Dinâmicas Imobiliárias e Redefinição da Estrutura Territorial: o caso da área metropolitana de Natal/RN. In: ENCONTRO NACIONAL DA ANPUR, 12, 2007, Belém. Anais eletrônicos... Belém: ANPUR, 2007. p.1-20.

LAMAS, José Manuel Ressano Garcia. Morfologia Urbana e desenho da cidade. $3^{\text {a }}$ edição. [Lisboa]: Fundação Calouste Gulbekian, 2004.

LEAL, Suely Maria Ribeiro. As veias abertas do planejamento urbano e a avalanche da governança do mercado. Miolo - Desenvolvimento, planejamento e governança. Rio de Janeiro: Letra Capital/ANPUR, 2015.

MARICATO, Erminia. Metrópoles desgovernadas. Estudos avançados v. 25, n. 71 (2011), Universidade de São Paulo. 2011.

PESSOA, Zoraide Souza. Uma análise do Movimento Pendular na definição da Espacialidade Territorial e Social Na RMNatal. XI Encontro da Associação Nacional de Pós-graduação e Pesquisa em Planejamento Urbano e Regional - ANPUR. Salvador (BA) 2005.

SILVA, Eugênio Ribeiro. Edifícios Icônicos e a Dinâmica Imobiliária de Natal/RN. Revista Mercator, Fortaleza, v. 14, n. 1, p. 47-59, jan. /abr. 2015.

Recebido em Maio de 2019

Aceito em Setembro de 2019

Publicado em Dezembro de 2019 